\title{
Cardiorespiratory fitness, pulmonary function and C-reactive protein levels in nonsmoking individuals with diabetes
}

\author{
C.O. Francisco ${ }^{1}$, A.M. Catai ${ }^{1}$, S.C.G. Moura-Tonello ${ }^{1}$, S.L.B. Lopes ${ }^{2}$, B.G. Benze ${ }^{3}$, \\ A.M. Del Vale ${ }^{2}$ and A.M.O. Leal ${ }^{2}$ \\ ${ }^{1}$ Departamento de Fisioterapia, Universidade Federal de São Carlos, São Carlos, SP, Brasil \\ ${ }^{2}$ Departamento de Medicina, Universidade Federal de São Carlos, São Carlos, SP, Brasil \\ ${ }^{3}$ Departamento de Estatística, Universidade Federal de São Carlos, São Carlos, SP, Brasil
}

\begin{abstract}
The objective of this study was to evaluate cardiorespiratory fitness and pulmonary function and the relationship with metabolic variables and $\mathrm{C}$-reactive protein (CRP) plasma levels in individuals with diabetes mellitus (DM). Nineteen men with diabetes and 19 age- and gender-matched control subjects were studied. All individuals were given incremental cardiopulmonary exercise and pulmonary function tests. In the exercise test, maximal workload $(158.3 \pm 22.3 \mathrm{vs} 135.1 \pm 25.2, \mathrm{P}=0.005)$, peak heart rate $\left(\mathrm{HR}_{\text {peak }}: 149 \pm 12\right.$ vs $\left.139 \pm 10, \mathrm{P}=0.009\right)$, peak oxygen uptake $\left(\mathrm{VO}_{2 \text { peak }}: 24.2 \pm 3.2\right.$ vs $\left.18.9 \pm 2.8, \mathrm{P}<0.001\right)$, and anaerobic threshold $\left(\mathrm{VO}_{2 \mathrm{VT}}\right.$ : $14.1 \pm 3.4$ vs $\left.12.2 \pm 2.2, \mathrm{P}=0.04\right)$ were significantly lower in individuals with diabetes than in control subjects. Pulmonary function test parameters, blood pressure, lipid profile (triglycerides, HDL, LDL, and total cholesterol), and CRP plasma levels were not different in control subjects and individuals with DM. No correlations were observed between hemoglobin A1C ( $\mathrm{HbA} 1 \mathrm{c})$, CRP and pulmonary function test and cardiopulmonary exercise test performance. In conclusion, the results demonstrate that nonsmoking individuals with DM have decreased cardiorespiratory fitness that is not correlated with resting pulmonary function parameters, $\mathrm{HbA} 1 \mathrm{c}$, and CRP plasma levels.
\end{abstract}

Key words: Diabetes mellitus; Pulmonary function test; Cardiopulmonary exercise test; Glycemic control; C-reactive protein

\section{Introduction}

Diabetes mellitus (DM) is associated with many wellknown comorbidities and chronic accompanying complications, including hypertension, dyslipidemia, microangiopathy, macroangiopathy, neuropathy, and subclinical pulmonary function impairment (1-3). Exercise is an important therapeutic strategy and has a positive impact on prevention of cardiovascular disease in patients with DM. In addition, reduction in lung volumes is reported in DM (2), and loss of exercise capacity is associated with DM and cardiovascular events $(3,4)$. However, few studies have investigated impairment of cardiorespiratory fitness and lung function at the same time in individuals with DM (2).

Lung involvement is prevalent in asymptomatic diabetics, affecting $60 \%$ of adults (5). Autopsy findings in the lungs of diabetic individuals have demonstrated thickening of the alveolar epithelium and pulmonary capillary basal laminae and pulmonary microangiopathy (6) probably associated with glycosylation of collagen in the chest and lung due to chronic hyperglycemia (7). These factors could have a negative impact on exercise capacity.

The reduced capacity to perform submaximal exercise in individuals with DM has been demonstrated by low peak oxygen uptake $\left(\mathrm{VO}_{2 \text { peak }}\right)$, qualitative difference in the rate of increase in oxygen uptake $\left(\mathrm{VO}_{2}\right)$ in association with slow $\mathrm{VO}_{2}$ kinetics, and increased ventilatory power requirement of the lung with incremental exercise (8).

Metabolic derangement and increased levels of acute and chronic systemic inflammatory mediators are important factors involved in the pathophysiology of diabetic chronic complications. Elevated glycemia and protein glycosylation may lead to vascular and endothelial dysfunction, consequent decreases of pulmonary function and ventilatory power, and low exercise capacity (9). Creactive protein (CRP) is a marker of systemic inflammation and has been associated with poor glycemic control and increased risk of cardiovascular disease (10).

Correspondence: C.O. Francisco, Departamento de Fisioterapia, Universidade Federal de São Carlos, Rod. Washington Luís, km 235, 13565-905 São Carlos, SP, Brasil. E-mail: cristinaft05@gmail.com 
However, the data regarding cardiopulmonary dysfunction and its underlying mechanisms in DM are still controversial.

The objective of this study was to evaluate cardiorespiratory fitness and pulmonary function and their relationship with metabolic variables and CRP plasma levels in nonsmoking individuals with DM. We hypothesized that DM causes alterations in pulmonary function and cardiorespiratory fitness and that glycemic control and inflammation may be associated with those alterations.

\section{Material and Methods}

\section{Subjects}

This case-controlled study was conducted in accordance with the standards required by Resolution 196/96 on research involving human subjects and approved by the Ethics Committee of the Universidade Federal de São Carlos (UFSCar; \#412/2010). Thirty-eight individuals participated in the study after providing written informed consent.

All subjects were free of overt coronary disease based on clinical evaluation and dynamic exercise stress test and sedentary electrocardiograms. Their functional aerobic classification was determined as very low, low, or reasonable $(11,12)$. Control subjects had a mean body mass index $(\mathrm{BMI})<29.9 \mathrm{~kg} / \mathrm{m}^{2}$ and individuals with $\mathrm{DM}$ were diagnosed according to the recommendations of the American Diabetes Association (1). BMI was not matched between DM and control subjects because obesity is a hallmark of clinical presentation and an important causal factor of diabetes in adults. Individuals with DM were medicated with metformin, gliclazide, and/or insulin for hyperglycemia, angiotensin-converting enzyme inhibitors for hypertension, and simvastatin for dyslipidemia. Exclusion criteria were smoking, anemia, alcoholism, use of anti-inflammatory or inhalable drugs, known respiratory and inflammatory diseases, congestive heart failure, and disability conditions precluding exercise or pulmonary function test.

\section{Experimental procedures}

Tests were performed in the morning. Subjects were requested to refrain from alcohol, caffeine, and exercise for $24 \mathrm{~h}$ before testing. On the experimental day, after 10$12 \mathrm{~h}$ of fasting, the subjects underwent anthropometrical evaluation, and blood samples were drawn for measurement of glycohemoglobin ( $\mathrm{HbA} 1 \mathrm{c})$, plasma CRP concentration, and lipid profile using an ADVIA 1800 Chemistry System (Siemens, USA).

Pulmonary function at rest. After a light breakfast, each subject underwent standardized pulmonary function tests (13) using a spirometry analyzer (CPX-D, Medical Graphics, USA). Slow vital capacity, inspiratory capacity, expiratory reserve volume, forced vital capacity (FVC), forced expiratory volume in $1 \mathrm{~s}\left(F E V_{1}\right), F E V_{1} / F V C$, forced mid-expiratory flow phase, peak expiratory flow, maximal voluntary ventilation, and tidal volume were measured. Absolute values were adjusted for age, gender, and height, and were reported as absolute values and as a percentage of predicted values based on data published by Pereira et al. (14).

Cardiopulmonary exercise test. An incremental exercise test was performed on a cycloergometer with electromagnetic braking (Quinton Corival 400, USA). Ventilatory and metabolic variables were continuously collected breath-by-breath and recorded with the metabolic unit (CPX/D). $\mathrm{VO}_{2}$, carbon dioxide production $\left(\mathrm{VCO}_{2}\right)$, minute ventilation (VE), and respiratory exchange ratio (RER) $\left(\mathrm{VCO}_{2} / \mathrm{VO}_{2}\right)$ were measured. Workload increases, ranging from 13-22 W/min, were determined for each subject as described by Wasserman et al. (15). $\mathrm{VO}_{2 \text { peak }}$ values were the mean of the last $30 \mathrm{~s}$ of exercise. $\mathrm{VO}_{2}$ at anaerobic threshold (VT) was determined using the ventilatory method (15) by three independent observers. During exercise, subjects maintained a speed of $60 \mathrm{rpm}$. Electrocardiograms and heart rate (HR) were continuously monitored and blood pressure was measured every 2 min. Testing was symptom-limited (12). It was interrupted when blood pressure reached the following limits: systolic blood pressure (SBP) higher than $200 \mathrm{mmHg}$ or diastolic blood pressure (DBP) higher than $120 \mathrm{mmHg}$, or when the subject complained of chest pain, dyspnea, and/or exhaustion evaluated on the Borg scale (CR10). It was assumed that $\mathrm{VO}_{2 \text { peak }}$ had been achieved when the period of increasing workload lasted only 8-12 min and the RER at exercise peak reached a value of 1.0 or more.

\section{Statistical analysis}

Results are reported as means \pm SD or median and range for parametric and nonparametric tests, respectively. Anderson-Darling and Levene tests were used to test the normality and homoscedasticity of distributions, respectively. Group differences in variables were compared using the Student $t$-test or the Mann-Whitney test. Relationships between variables were determined using the Pearson correlation coefficient ( $r$ ). $P<0.05$ was considered to be statistically significant. All analyses were performed using the Minitab software program version 15.0 for Windows (Minitab Inc., USA). The power of the study variables was over 0.8 .

\section{Results}

Nineteen men, $51.2 \pm 5.9$ years of age, with DM (17 with type 2 and 2 with type 1), and 19 age- and gendermatched control subjects, $48.8 \pm 7.5$ years of age, participated in the study. SBP and DBP, lipid profile (triglycerides, HDL, LDL, and total cholesterol), and CRP plasma levels were similar in control subjects and individuals with DM (Table 1). Two individuals in each group were on simvastatin therapy. BMI, resting HR, and $\mathrm{HbA} 1 \mathrm{c}$ were significantly higher in individuals with DM 
Table 1. Clinical and laboratory characteristics.

\begin{tabular}{lcc}
\hline & Control $(\mathrm{n}=19)$ & DM $(\mathrm{n}=19)$ \\
\hline Age (years) & $48.8 \pm 7.5$ & $51.2 \pm 5.9$ \\
Weight $(\mathrm{kg})$ & $76.6 \pm 8.9$ & $85.5 \pm 13.7^{\mathrm{a}}$ \\
BMI $\left(\mathrm{kg} / \mathrm{m}^{2}\right)$ & $25.9(20.7-28.8)$ & $29.5(20.9-38.2)^{\mathrm{a}}$ \\
Duration of DM (years) & - & $11 \pm 1.5$ \\
Resting HR (bpm) & $71 \pm 9$ & $78 \pm 10^{\mathrm{a}}$ \\
Resting SBP (mmHg) & $130(110-139)$ & $120(100-160)$ \\
Resting DBP (mmHg) & $80(70-100)$ & $80(70-110)$ \\
HbA1c $\%)$ & $5.8(4.8-6.4 \%)$ & $8.8(6-12.9 \%)^{\mathrm{b}}$ \\
Total cholesterol (mg/dL) & $192(130-378)$ & $181(154-290)$ \\
HDL cholesterol (mg/dL) & $48.0 \pm 10.6$ & $45.6 \pm 11.6$ \\
LDL cholesterol (mg/dL) & $121.6 \pm 35.6$ & $113.8 \pm 30.7$ \\
Triglycerides $(\mathrm{mg} / \mathrm{dL})$ & $138(57-526)$ & $140(78.2-310)$ \\
CRP (mg/L) & $0.5(0.1-2.5)$ & $0.4(0.1-2.7)$ \\
\hline
\end{tabular}

Data are reported as means \pm SD for parametric distribution of values or median and range for non-parametric distribution of values. DM: diabetes mellitus; BMI: body mass index; HR: heart rate; SBP: systolic blood pressure; DBP: diastolic blood pressure; HbA1c: glycohemoglobin; HDL and LDL: high- and low-density lipoprotein; CRP: C-reactive protein. Differences between groups were tested using the Student $t$-test (parametric distribution) or the Mann-Whitney test (non-parametric distribution). ${ }^{a} \mathrm{P}<0.05 ;{ }^{\mathrm{b}} \mathrm{P}<0.001$.

than in controls (Table 1). HbA1c concentration was chosen as the estimate of long-term glycemic control.

Table 2 shows cardiopulmonary exercise test results. The ventilatory equivalents for oxygen $\left(\mathrm{VE} / \mathrm{NO}_{2}\right)$ and carbon dioxide $\left(\mathrm{VE} / \mathrm{VCO}_{2}\right)$ at $\mathrm{VT}$ were significantly higher in individuals with $\mathrm{DM}$ than in controls. $\mathrm{VO}_{2}$ at $\mathrm{VT}$, workload, $\mathrm{HR}$, and $\mathrm{VO}_{2}$ at the exercise peak were significantly lower in individuals with DM than in controls. The workload adjusted for weight was lower in individuals with DM at VT and at exercise peak than in controls. There were no other differences in cardiorespiratory variables at exercise peak between the groups. No correlations were observed between the cardiovascular
( $\mathrm{HR}$ and blood pressure) and ventilatory $\left(\mathrm{VO}_{2}, \mathrm{VCO}_{2}, \mathrm{VE}\right.$, $\mathrm{RER}, \mathrm{VE} / \mathrm{VO}_{2}, \mathrm{VE} / \mathrm{VCO}_{2}$ ) parameters of the cardiopulmonary exercise test. The pulmonary function test parameters were similar in control subjects and individuals with DM (Table 3). No correlations were observed between $\mathrm{HbA} 1 \mathrm{c}$ or CRP and pulmonary function tests and cardiopulmonary exercise test parameters.

\section{Discussion}

The results showed that nonsmoking individuals with DM have decreased cardiorespiratory fitness that is not correlated with resting pulmonary function parameters,

Table 2. Cardiopulmonary exercise test parameters.

\begin{tabular}{|c|c|c|c|c|}
\hline & \multicolumn{2}{|c|}{ VT } & \multicolumn{2}{|c|}{ Peak } \\
\hline & Control & DM & Control & DM \\
\hline Workload (W) & $82.5 \pm 19.8$ & $72.2 \pm 17.8$ & $158.3 \pm 22.3$ & $135.1 \pm 25.2^{\mathrm{a}}$ \\
\hline $\mathrm{HR}(\mathrm{bpm})$ & $102 \pm 14$ & $105 \pm 10$ & $149 \pm 12$ & $139 \pm 10^{a}$ \\
\hline $\mathrm{SBP}(\mathrm{mmHg})$ & $155 \pm 16.8$ & $162 \pm 16.7$ & $183 \pm 13.8$ & $186 \pm 17.7$ \\
\hline $\mathrm{DBP}(\mathrm{mmHg})$ & $90(80-100)$ & $90(80-120)$ & $100(80-110)$ & $100(80-130)$ \\
\hline $\mathrm{VO}_{2}\left(\mathrm{~mL} \cdot \mathrm{kg}^{-1} \cdot \mathrm{min}^{-1}\right)$ & $14.1 \pm 3.4$ & $12.2 \pm 2.2^{\mathrm{a}}$ & $24.2 \pm 3.2$ & $18.9 \pm 2.8^{\mathrm{b}}$ \\
\hline $\mathrm{VCO}_{2}(\mathrm{~L} / \mathrm{min})$ & $0.9 \pm 0.2$ & $0.9 \pm 0.2$ & $2 \pm 0.3$ & $1.8 \pm 0.3$ \\
\hline VE (L/min) & $25.9 \pm 5.7$ & $26.8 \pm 4.9$ & $57.6 \pm 11.8$ & $55.7 \pm 12.6$ \\
\hline $\mathrm{VE} / \mathrm{NO}_{2}$ & $24(21-29)$ & $26(23-31)^{a}$ & $31.4 \pm 5.1$ & $34.3 \pm 5.6$ \\
\hline $\mathrm{VE} / \mathrm{VCO}_{2}$ & $28(22-34)$ & $29(26-34)^{b}$ & $28.9 \pm 4.4$ & $29.8 \pm 3.13$ \\
\hline Work/weight (W/kg) & $1.1 \pm 0.3$ & $0.9 \pm 0.2^{\mathrm{a}}$ & $2.1 \pm 0.3$ & $1.6 \pm 0.2^{\mathrm{b}}$ \\
\hline
\end{tabular}

Data are reported as means $\pm S D$ for parametric distribution of values or median and range for non-parametric distribution of values. VT: anaerobic threshold; DM: diabetes mellitus; HR: heart rate; SBP: systolic blood pressure; DBP: diastolic blood pressure; VO ${ }_{2}$ : oxygen uptake; $\mathrm{VCO}_{2}$ : carbon dioxide production; $\mathrm{VE}$ : minute ventilation; $\mathrm{VE} / \mathrm{VO}_{2}$ : ventilatory equivalent for oxygen; $\mathrm{VE} / \mathrm{VCO}$ : ventilatory equivalent for carbon dioxide. Differences between groups were tested using the Student $t$-test (parametric distribution) or the Mann-Whitney test (non-parametric distribution). ${ }^{a} \mathrm{P}<0.05 ;{ }^{\mathrm{b}} \mathrm{P}<0.001$. 
Table 3. Pulmonary function test parameters.

\begin{tabular}{|c|c|c|}
\hline & Control & DM \\
\hline SVC (L) & $4.6 \pm 0.6$ & $4.4 \pm 0.9$ \\
\hline SVC (\% pred) & $100.6 \pm 12.5$ & $99.5 \pm 14.1$ \\
\hline $\mathrm{IC}(\mathrm{L})$ & $3.4 \pm 0.6$ & $3.6 \pm 0.7$ \\
\hline IC (\% pred) & $96.0 \pm 13.9$ & $102.1 \pm 15.7$ \\
\hline ERV (L) & $1.1 \pm 0.4$ & $2 \pm 0.4$ \\
\hline ERV (\% pred) & $132.3 \pm 48.8$ & $110.3 \pm 54.2$ \\
\hline FVC (L) & $4.6 \pm 0.7$ & $4.6 \pm 0.8$ \\
\hline FVC (\% pred) & $101.5 \pm 9.1$ & $104 \pm 13.1$ \\
\hline $\mathrm{FEV}_{1}(\mathrm{~L})$ & $3.6 \pm 0.5$ & $3.7 \pm 0.6$ \\
\hline $\mathrm{FEV}_{1}(\%$ pred $)$ & $99.8 \pm 11.1$ & $104.6 \pm 13.0$ \\
\hline $\mathrm{FEV}_{1} / \mathrm{FVC}$ & $80.4 \pm 5.1$ & $82.2 \pm 3.9$ \\
\hline $\mathrm{FEF}_{25-75 \%}(\mathrm{~L} / \mathrm{min})$ & $3.6 \pm 1$ & $4.0 \pm 1$ \\
\hline $\mathrm{FEF}_{25-75 \%}(\%$ pred $)$ & $101.1 \pm 28.9$ & $116.1 \pm 25.2$ \\
\hline PEF (L/min) & $8.8 \pm 2.2$ & $8.2 \pm 1.6$ \\
\hline PEF (\% pred) & $95.2 \pm 21.8$ & $90.4 \pm 15.4$ \\
\hline $\mathrm{MVV}(\mathrm{L})$ & $173.1 \pm 32.6$ & $160.8 \pm 30.7$ \\
\hline MVV (\% pred) & $113.6 \pm 18.7$ & $107.2 \pm 14.4$ \\
\hline TV (L/min) & $1.8 \pm 0.4$ & $1.7 \pm 0.4$ \\
\hline
\end{tabular}

Data are reported as means $\pm S D$. SVC: slow vital capacity; IC: inspiratory capacity; ERV: expiratory reserve volume; FVC: forced vital capacity; $\mathrm{FEV}_{1}$ : forced expiratory volume in $1 \mathrm{~s}$;

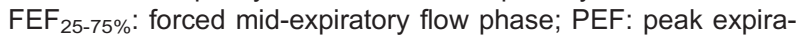
tory flow; MVV: maximal voluntary ventilation; TV: tidal volume. There were no statistically significant differences between groups ( $\mathrm{P}>0.05$, Student $t$-test).

HbA1c, or CRP plasma levels. No differences in pulmonary function variables were observed between the groups, although subjects with DM had a higher mean BMI than controls. As previously reported (16), there was a negative relationship between pulmonary function values and BMI only at a BMI over $45 \mathrm{~kg} / \mathrm{m}^{2}$.

Previous studies have also demonstrated reduced $\mathrm{VO}_{2}$ values at $\mathrm{VT}$ and $\mathrm{VO}_{2 \text { peak }}$ in subjects with diabetes $(2,17,18)$. The results of this study showed higher values of $\mathrm{VE} / \mathrm{VO}_{2}$ and $\mathrm{VE} / \mathrm{VCO}_{2}$ at $\mathrm{VT}$ in subjects with diabetes than in control subjects. These findings suggest reduced ventilatory efficiency in these individuals (15).

Hyperglycemia impairs vascular and endothelial function (9) and has deleterious effects in the regulation of oxygen transport and utilization (17) leading to a leftward shift in the oxyhemoglobin dissociation curve, which could cause a reduction in VT and peak $\mathrm{VO}_{2}$ (15). Autopsy findings in subjects with DM showed thickening of the alveolar epithelia and pulmonary capillary basal laminae and microangiopathy (2) that may affect gas exchange and contribute to reduction of ventilatory efficiency (19). Reduced ventilatory response in DM may be the result of reduced cardiac output that impairs pulmonary blood flow distribution and lung perfusion reducing uniformity of the regional ventilation-perfusion relationships (20).

$\mathrm{DM}$ is associated with alterations in peripheral $\mathrm{O}_{2}$ extraction and delivery (18) and abnormal peripheral vasodilatation at rest and during exercise (4). The reduced weight-adjusted workload in the present study might indicate a reduction of cardiac output and reduced rate of circulatory adjustment to an increase in workload in subjects with DM as previously suggested (4).

During exercise, cardiovascular response is determined by central and reflex neural mechanisms. At the beginning of exercise, decreased parasympathetic neural activity controls the rate of heart contractility. In addition, increased sympathetic neural activity controls the heart and the caliber, resistance, and capacitance of vessels in the systemic circulation (21). Autonomic neuropathy impairs hemodynamic regulation during exercise in DM $(9,17)$. Low HR peak values previously observed in patients with diabetes $(2,17)$ were probably due to subclinical autonomic dysfunction (9). On the other hand, neural reflexes and muscle metaboreflexes determine the level of autonomic activity in the circulatory system and are related to mechanical and metabolic activity of the contracting muscle (21), contributing to vascular regulation (22). In diseases where vascular function is impaired, coronary vasoconstriction triggered by muscle metaboreflexes contributes to reduction in exercise capacity (22). It has been demonstrated that young individuals with type 1 DM have blunted blood pressure responses to metaboreflex activation due to reduced capacity to increase sympathetic tone (23). However, this mechanism has not been explored in type 2 DM.

Low-grade inflammation is most likely not the predominant causal factor of decreased fitness in DM because subjects in our sample had DM and CRP levels that were within the normal range. However, previous studies have reported elevated plasma CRP levels in subjects with DM $(3,10)$. Smoking status and characteristics, such as duration of smoking, pack-years smoked, and duration of abstinence from smoking, are important factors, but not usually controlled in studies that evaluate the influence of inflammatory markers and cardiorespiratory fitness and pulmonary function (24). These factors per se are closely associated with various markers of inflammation, including CRP, in men (25). In this study, current smoking status and a past history of smoking were exclusion criteria to minimize this confounder. However, we cannot exclude the influence of other possible confounders, such as the use of medications. It is impossible to estimate their effects, if any, particularly during exercise. In any case, it is known that medications commonly used by diabetic individuals, such as hypoglycemic drugs, angiotensin-converting enzyme inhibitors, and simvastatin can potentially affect CRP levels (26-28). On the other hand, high CRP levels have been observed in diabetic patients treated with oral hypoglycemic drugs and/or insulin (29). In addition, diabetic individuals evaluated in previous studies that found correlations between CRP and fitness or pulmonary function were 
receiving pharmacological treatments or were not excluded from the study protocol because of the treatment $(3,30)$. In the present study, all medications were discontinued for at least $10 \mathrm{~h}$ before blood collection, but because of ethical issues, it was not possible to discontinue the drugs for a longer time.

There are conflicting data regarding the impact of glycemic control on exercise capacity and pulmonary function in subjects with DM. It has been demonstrated that increases in $\mathrm{HbA}_{\mathrm{c}}$ levels and poor glycemic control are associated with altered pulmonary function and exercise capacity $(9,17)$. The results of the present study are in accordance with other studies that did not demonstrate any significant relationship between $\mathrm{HbA}_{\mathrm{c}}$ and exercise

\section{References}

1. Report of the expert committee on the diagnosis and classification of diabetes mellitus. Diabetes Care 2003; 26 (Suppl 1): S5-S20.

2. Benbassat CA, Stern E, Kramer M, Lebzelter J, Blum I, Fink G. Pulmonary function in patients with diabetes mellitus. Am J Med Sci 2001; 322: 127-132, doi: 10.1097/ 00000441-200109000-00003.

3. McGavock JM, Mandic S, Vonder Muhll I, Lewanczuk RZ, Quinney HA, Taylor DA, et al. Low cardiorespiratory fitness is associated with elevated C-reactive protein levels in women with type 2 diabetes. Diabetes Care 2004; 27: 320325, doi: 10.2337/diacare.27.2.320.

4. Regensteiner JG. Type 2 diabetes mellitus and cardiovascular exercise performance. Rev Endocr Metab Disord 2004; 5: 269-276, doi: 10.1023/B:REMD.0000032416. 13070.01.

5. Cooper BG, Taylor R, Alberti KG, Gibson GJ. Lung function in patients with diabetes mellitus. Respir Med 1990; 84: 235239, doi: 10.1016/S0954-6111(08)80041-8.

6. Kodolova IM, Lysenko LV, Saltykov BB. [Changes in the lungs in diabetes mellitus]. Arkh Patol 1982; 44: 35-40.

7. Cavan DA, Parkes A, O'Donnell MJ, Freeman W, Cayton RM. Lung function and diabetes. Respir Med 1991; 85: 257258, doi: 10.1016/S0954-6111(06)80092-2.

8. Regensteiner JG, Bauer TA, Reusch JE, Brandenburg SL, Sippel JM, Vogelsong AM, et al. Abnormal oxygen uptake kinetic responses in women with type II diabetes mellitus. J Appl Physiol 1998; 85: 310-317.

9. Fang ZY, Sharman J, Prins JB, Marwick TH. Determinants of exercise capacity in patients with type 2 diabetes. Diabetes Care 2005; 28: 1643-1648, doi: 10.2337/diacare. 28.7.1643.

10. King DE, Mainous AG III, Buchanan TA, Pearson WS. C-reactive protein and glycemic control in adults with diabetes. Diabetes Care 2003; 26: 1535-1539, doi: 10.2337/ diacare.26.5.1535.

11. American Heart Association. Exercise testing and training of apparently health individuals: a handbook for physicians. Dallas: American Heart Association; 1972.

12. Mezzani A, Agostoni P, Cohen-Solal A, Corra U, Jegier A, Kouidi $E$, et al. Standards for the use of cardiopulmonary exercise testing for the functional evaluation of cardiac capacity $(17)$ or pulmonary function $(2,19)$ in adults with DM.

The small number of subjects that were enrolled is a limitation of this study. The major strength is the simultaneous evaluation of pulmonary function, cardiorespiratory fitness, and inflammation markers in a wellcontrolled sample of nonsmoking diabetic individuals.

In conclusion, subjects with DM had decreased cardiorespiratory fitness that was not correlated with CRP levels, HbA1c, or pulmonary function parameters. The mechanisms of this disorder need clarification.

\section{Acknowledgments}

Research supported by FAPESP (\#2011/51007-0).

patients: a report from the Exercise Physiology Section of the European Association for Cardiovascular Prevention and Rehabilitation. Eur J Cardiovasc Prev Rehabil 2009; 16: 249-267, doi: 10.1097/HJR.0b013e32832914c8.

13. Standardization of Spirometry, 1994 Update. American Thoracic Society. Am J Respir Crit Care Med 1995; 152: 1107-1136, doi: 10.1164/ajrccm.152.3.7663792.

14. Pereira C, Barreto S, Simöes J, Pereira F, Gerstler J, Nakatani J. Reference values for spirometry in Brazilian adults. J Pneumol 2014; 18: 10-22.

15. Wasserman K, Hansen JE, Sue DY, Stringer WW, Whipp BJ. Principles of exercise testing and interpretation. 3rd edn. Philadelphia: Williams \& Wilkns; 1999.

16. D'Avila Melo SM, Melo VA, Menezes Filho RS, Santos FA. Effects of progressive increase in body weight on lung function in six groups of body mass index. Rev Assoc Med Bras 2011; 57: 509-515, doi: 10.1590/S0104-423020110 00500007.

17. Brassard P, Ferland A, Bogaty P, Desmeules M, Jobin J, Poirier $P$. Influence of glycemic control on pulmonary function and heart rate in response to exercise in subjects with type 2 diabetes mellitus. Metabolism 2006; 55: 15321537, doi: 10.1016/j.metabol.2006.06.025.

18. Baldi JC, Aoina JL, Oxenham HC, Bagg W, Doughty RN. Reduced exercise arteriovenous $\mathrm{O}_{2}$ difference in type 2 diabetes. J Appl Physiol 2003; 94: 1033-1038.

19. Guvener N, Tutuncu NB, Akcay S, Eyuboglu F, Gokcel A. Alveolar gas exchange in patients with type 2 diabetes mellitus. Endocr J 2003; 50: 663-667, doi: 10.1507/ endocrj.50.663.

20. Tantucci C, Bottini P, Dottorini ML, Puxeddu E, Casucci G, Scionti $\mathrm{L}$, et al. Ventilatory response to exercise in diabetic subjects with autonomic neuropathy. J Appl Physiol 1996; 81: 1978-1986.

21. Mitchell JH. J.B. Wolffe memorial lecture. Neural control of the circulation during exercise. Med Sci Sports Exerc 1990; 22: 141-154, doi: 10.1249/00005768-199004000-00535.

22. Leuenberger UA. The muscle metaboreflex: reining in the heart? J Appl Physiol 2010; 109: 263-264, doi: 10.1152/ japplphysiol.00547.2010.

23. Roberto S, Marongiu E, Pinna M, Angius L, Olla S, Bassareo $\mathrm{P}$, et al. Altered hemodynamics during muscle 
metaboreflex in young type 1 diabetes patients. J Appl Physiol 2012; 113: 1323-1331, doi: 10.1152/japplphysiol. 00280.2012.

24. Louie D. The effects of cigarette smoking on cardiopulmonary function and exercise tolerance in teenagers. Can Respir J 2001; 8: 289-291.

25. Frohlich M, Sund M, Lowel H, Imhof A, Hoffmeister A, Koenig $W$. Independent association of various smoking characteristics with markers of systemic inflammation in men. Results from a representative sample of the general population (MONICA Augsburg Survey 1994/95). Eur Heart J 2003; 24: 1365-1372, doi: 10.1016/S0195-668X(03)00260-4.

26. Farah R, Shurtz-Swirski R, Lapin O. Intensification of oxidative stress and inflammation in type 2 diabetes despite antihyperglycemic treatment. Cardiovasc Diabetol 2008; 7: 20, doi: 10.1186/1475-2840-7-20.

27. Palmas W, Ma S, Psaty B, Goff DC Jr, Darwin C, Barr RG. Antihypertensive medications and C-reactive protein in the multi-ethnic study of atherosclerosis. Am J Hypertens 2007; 20: 233-241, doi: 10.1016/j.amjhyper.2006.08.006.

28. Plenge JK, Hernandez TL, Weil KM, Poirier P, Grunwald GK, Marcovina SM, et al. Simvastatin lowers C-reactive protein within 14 days: an effect independent of low-density lipoprotein cholesterol reduction. Circulation 2002; 106: 1447-1452, doi: 10.1161/01.CIR.0000029743.68247.31.

29. Fronczyk A, Moleda P, Safranow K, Piechota W, Majkowska $\mathrm{L}$. Increased concentration of C-reactive protein in obese patients with type 2 diabetes is associated with obesity and presence of diabetes but not with macrovascular and microvascular complications or glycemic control. Inflammation 2014; 37: 349-357, doi: 10.1007/s10753-013-9746-4.

30. Lee CC, Adler Al, Sandhu MS, Sharp SJ, Forouhi NG, Erqou S, et al. Association of C-reactive protein with type 2 diabetes: prospective analysis and meta-analysis. Diabetologia 2009; 52: 1040-1047, doi: 10.1007/s00125009-1338-3. 